\title{
SISTEM INFORMASI AKUNTANSI BERBASIS WEB PADA PERUSAHAAN JASA TENAGA KERJA
}

\author{
Bintang Chandra ${ }^{1)}$ Hendro Poerbo ${ }^{2)}$ \\ ${ }^{1,2)}$ Sistem Informasi Universitas Machung, Villa Puncak Tidar N-1 Malang \\ email:321510003@student.machung.ac.id ${ }^{1}$, hendro.poerbo@machung.ac.id ${ }^{2)}$
}

\begin{abstract}
Abstraksi
PT Lia Central Utama merupakan perusahaan jasa tenaga kerja Indonesia yang berpusat di Kota Tanjungpinang dan memiliki salah satu cabang di Kota Malang. Perusahaan cabang di Kota Malang ini masih menggunakan proses manual untuk pencatatan keuangan perusahaan. Pada saat ini proses pengelolaan data keuangan di PT. Lia Central Utama cabang Kota Malang masih menerapkan proses manual, yakni dengan cara mencatat data transaksi di jurnal harian, kemudian direkap berdasarkan siklus bulanan dengan cara membuat laporan keuangan menggunakan aplikasi microsoft excel. Perhitungan rinci serta pelaporan akuntansi dalam manajemen keuangan belum tersedia sehingga menyulitkan perusahan pusat dalam memantau perkembangan finansial. Dari latar belakang tersebut dapat berdampak kepada kualitas laporan keuangan, dimana laporan keuangan sangat dibutuhkan perusahaan pusat dalam memantau perkembangan kantor cabang serta untuk mengambil kebijakan dalam memajukan perusahaan kedepannya. Hal utama yang diperlukan perusahaan yakni menerapkan sistem perlaporan akuntansi untuk mendapatkan laporan keuangan secara rinci. Pengembangan sistem dilakukan dengan metode System Development Life Cycle (SDLC) yang dibagi dalam lima fase, yaitu perencanaan, analisis, desain, implementasi, serta dilakukan tahap testing. Sistem ini diharapkan dapat membantu PT. Lia Central Utama khususnya cabang Kota Malang untuk memantau keuangan perusahaan. Hasil akhir yang didapat adalah pelaporan Jurnal Umum, Buku Besar, Neraca Saldo, Jurnal Penyesuaian, Neraca Saldo sesudah Penyesuaian, Laporan Laba Rugi, Laporan Perubahan Modal, dan Neraca Akhir.
\end{abstract}

\section{Kata Kunci :}

Akuntansi, tki, jasa, php, mysql

\begin{abstract}
PT. Lia Central Utama is an Indonesian labor services company based in Tanjungpinang City and has one branch in Malang City. This branch company in Malang City still uses a manual process for recording company finances. At this time the process of managing financial data at PT. Lia Central Utama branch of Malang City still applies manual processes, namely by recording transaction data in daily journals, then recapitating based on monthly cycles by making financial statements using the Microsoft Excel application. Detailed calculations and accounting reporting in financial management are not yet available, making it difficult for central companies to monitor financial developments. From this background it can have an impact on the quality of financial statements, where financial statements are needed by central companies in monitoring the development of branch offices and for taking policies in advancing the company going forward. The main thing that companies need is to implement an accounting reporting system to obtain detailed financial statements. System development is done by the System Development Life Cycle (SDLC) method which is divided into five phases, namely planning, analysis, design, implementation, and testing phases. This system is expected to help PT. Lia Central Utama especially the branch of Malang City to monitor the company's finances. The final results obtained are reporting of General Journal, Ledger, Balance Sheet, Adjustment Journal, Post Adjustment Balance Sheet, Profit and Loss Statement, Capital Change Report, and Final Balance Sheet.
\end{abstract}

Keywords :

Accounting, services, system development life cycle, php, mysql 


\section{PENDAHULUAN}

Perkembangan teknologi saat ini semakin berkembang pesat yang menjadikan masyarakat dapat mengakses informasi dimana saja dengan cepat dan efisien. Penerapan teknologi ini salah satunya adalah penggunaan sistem berbasis website yang fungsinya memberikan informasi kepada masyarakat. Sistem berbasis website banyak diterapkan pada perusahaan hingga lembaga-lembaga yang ada. Penerapan sistem berbasis website ini bahkan penting untuk diterapkan pada perusahaan, salah satunya Perusahaan Jasa Tenaga Kerja Indonesia (PJTKI). PJTKI adalah institusi swasta yang diberi monopoli oleh Pemerintah Indonesia untuk merekrut dan memroses pengiriman tenaga kerja Indonesia ke negara-negara lain, dan menjamin penempatan tenaga kerja[1]. PT Lia Central Utama merupakan perusahaan jasa tenaga kerja Indonesia yang berpusat di Kota Tanjungpinang dan memiliki salah satu cabang di Kota Malang. Perusahaan cabang di Kota Malang ini masih menggunakan proses manual untuk pencatatan keuangan perusahaan. Pada saat ini proses pengelolaan data keuangan di PT. Lia Central Utama cabang Kota Malang masih menerapkan proses manual, yakni dengan cara mencatat data transaksi di jurnal harian, kemudian direkap berdasarkan siklus bulanan dengan cara membuat laporan keuangan menggunakan aplikasi microsoft excel. Perhitungan rinci serta pelaporan akuntansi dalam manajemen keuangan belum tersedia sehingga menyulitkan perusahan pusat dalam memantau perkembangan finansial.

Dari permasalahan tersebut dapat berdampak kepada kualitas laporan keuangan, dimana laporan keuangan sangat dibutuhkan perusahaan pusat dalam memantau perkembangan kantor cabang serta untuk mengambil kebijakan dalam memajukan perusahaan kedepannya. Berdasarkan masalah itu, penting bagi perusahaan untuk menerapkan sistem informasi akuntansi yang berfungsi untuk mendukung kelancaran proses bisnis perusahaan, peningkatan kualitas laporan, dan juga sebagai langkah awal terhadap perubahan sistem lama yang digunakan oleh PT. Lia Central Utama. Dalam merancang pembuatan sistem ini akan menggunakan metode SDLC (Systems Development Life Cycle) yang memiliki tahapan planning, analisis, desain, implementasi, dan testing. Berdasarkan hasil pada tahap analisis nantinya, maka akan diketahui kebutuhan fungsional mengenai sistem akuntansi yang cocok untuk PT Lia Central Utama. Melihat hasil analisis tersebut selanjutnya akan dibuatkan desain rancangan sistem serta mengintegrasikan dengan data keuangan yang telah ada, sehingga didapatkan hasil berupa website Sistem Informasi Akuntansi perusahaan jasa tenaga kerja Indonesia. 
URL : https://jurnal.machung.ac.id/index.php/kurawal

\section{METODE / ALGORITMA}

Dalam mengembangkan sistem diperlukan sebuah metode yang digunakan sebagai panduan agar proses pengembangan dapat dilakukan dengan terstruktur dan sesuai dengan apa yang diharapkan. Metode yang digunakan dalam pengembangan sistem informasi akuntansi pada perusahaan jasa tenaga kerja Indonesia ini adalah dengan menggunakan SDLC (System Development Life Cycle), dimana pengembangan dibagi dalam tahap-tahap yang ditentukan, yaitu perencanaan, analisis, desain, implementasi, dan testing. System Development Life Cycle atau sering disingkat dengan SDLC merupakan pengembangan yang berfungsi sebagai sebuah mekanisme untuk mengidentifikasikan perangkat lunak[2]. Penggunaan metode ini sangat cocok karena pada SDLC telah mencakup tahapan yang cukup rinci, sehingga dalam merancang sebuah sistem akan didapatkan hasil yang terstruktur. Berikut adalah rincian dari tahapan melakukan perancangan sistem dengan menggunakan metodologi SDLC (System Development Life Cycle).

Tabel 1 Metode Perancangan

\begin{tabular}{|c|c|c|}
\hline Tahapan & Kegiatan & Cara/Tools \\
\hline Perencanaan & $\begin{array}{l}\text { - Pengumpulan Data } \\
\text { - Menentukan business } \\
\text { function }\end{array}$ & $\begin{array}{l}\text { - } \text { Interview } \\
\text { - Dokumentasi } \\
\text { - Konsultasi }\end{array}$ \\
\hline Analisis & $\begin{array}{l}\text { - Identifikasi masalah } \\
\text { - Analisis kebutuhan }\end{array}$ & $\begin{array}{l}\text { - Survey keadaan perusahaan } \\
\text { - Interview } \\
\text { - Konsultasi }\end{array}$ \\
\hline Desain & $\begin{array}{l}\text { - Workflow } \\
\text { - Use Case Diagram } \\
\text { - Diagram Aktivitas } \\
\text { - Desain } \\
\text { - Database/ERD } \\
\text { - Desain UI/UX } \\
\text { - Menentukan } \\
\text { Template }\end{array}$ & $\begin{array}{l}\text { - Membuat workflow sistem baru } \\
\text { - Menggambarkan use case diagram untuk setiap siklus } \\
\text { - } \text { akuntansi } \\
\text { - Menjabarkan aktivitas tiap proses untuk sistem } \\
\text { - Menghubungkan dengan database yang telah dibuat } \\
\text { - Membuat mockup desain input dan output } \\
\text { - Mesain interface }\end{array}$ \\
\hline Implementasi & $\begin{array}{l}\text { - Membuat sistem } \\
\text { - Styling sistem }\end{array}$ & $\begin{array}{l}\text { - Coding } \\
\text { - CSS Style }\end{array}$ \\
\hline Testing & - Testing bug sistem & - Website testing \\
\hline
\end{tabular}


URL : https://jurnal.machung.ac.id/index.php/kurawal

\section{HASIL DAN PEMBAHASAN}

\subsection{Tahap Perencanaan}

Tahap ini merupakan tahap dasar dalam menetapkan tujuan yang harus dilakukan dalam membuat sistem. Tahap perencanaan bertujuan untuk memberikan pedoman sebagai langkah awal agar keseluruhan proses berjalan dengan efektif dan akurat sesuai dengan hasil yang ingin dicapai.

Untuk mengembangkan dan membangun sistem informasi akuntansi berbasis web pada PT. Lia Central Utama Cabang Kota Malang, tahap perencanaan dimulai dengan melakukan pengumpulan data dan menentukan proses bisnis.

Pada pengumpulan data dibutuhkan untuk mengumpulkan semua data keuangan yang berkaitan dengan kebutuhan agar dapat diproses lebih lanjut untuk menentukan fungsi bisnis yang akan dijalankan sistem. Selanjutnya akan dilakukan analisis untuk mendapatkan hasil identifikasi. Metode pengumpulan data yang digunakan dalam perancangan sistem informasi akuntansi berbasis web pada PT. Lia Central Utama cabang Kota Malang adalah dengan konsultasi dan wawancara yang dilanjutkan dengan mendokumentasi dokumen yang terkait topik penelitian seperti invoice dan kwitansi. Kegiatan wawancara dilakukan dengan narasumber yakni Bapak Kukuh Catur D. H., S.Kom yang merupakan Admin dan Keuangan PT. Lia Central Utama cabang Kota Malang. Narasumber terkait sangat memahami betul mengenai proses bisnis perusahaan terutama dalam hal keuangan perusahaan. Semua data yang diperoleh dari hasil wawancara akan digunakan dalam tahap analisis serta desain sistem. Hasil yang didapatkan berdasarkan wawancara dengan Admin dan Keuangan perusahaan, dalam merekap semua transaksi masih mencatat secara manual pada buku keuangan serta mengumpulkan bukti transaksi dalam satu bundle dan dibedakan berdasarkan periode transaksi.

\subsection{Tahap Analisis}

Banyak perubahan yang dilakukan dalam proses pecatatan keuangan nantinya, karena sudah tidak memerlukan proses manual yang mana nantinya dari proses merekap transaksi harian dan bulanan hingga menampilkan laporan akan dilakukan dengan menggunakan sistem. Sistem yang dihasilkan juga lebih baik, karena telah memenuhi prosedur pelaporan akuntansi mulai dari jurnal umum, buku besar, neraca saldo, jurnal penyesuaian, neraca saldo sesudah penyesuaian, laporan laba rugi, laporan perubahan modal, hingga neraca akhir. Secara garis 
URL : https://jurnal.machung.ac.id/index.php/kurawal

besar, alur mengenai sistem baru yang dibuat akan digambarkan pada gambar workflow sistem baru.

Berdasarkan hasil workflow tersebut, maka dapat ditentukan kebutuhan fungsional dari sistem dan pengguna yang masuk ke dalam sistem tersebut. Berikut kebutuhan fungsional yang dapat dilihat pada tabel Specific Requirements.

Tabel 2 Specific Requirements

\begin{tabular}{|l|l|}
\hline \multicolumn{1}{|c|}{ Parameter } & \multicolumn{1}{|c|}{ Keterangan } \\
\hline Login & $\begin{array}{l}\text { Admin dan Staff dapat masuk ke dalam sistem sesuai } \\
\text { hak akses masing-masing. }\end{array}$ \\
\hline Form Input & Admin dapat menginputkan data master serta transaksi. \\
\hline Tabel View & $\begin{array}{l}\text { Admin dapat melihat tabel dari data yang telah } \\
\text { diinputkan, sedangkan staff dapat melihat beberapa tabel } \\
\text { sesuai hak akses dari data yang telah diinput oleh admin. }\end{array}$ \\
\hline Pelaporan & $\begin{array}{l}\text { Admin dapat melihat pelaporan akuntansi sesuai periode } \\
\text { yang dipilih yakni Jurnal Umum, Buku Besar, Neraca } \\
\text { Saldo, Jurnal Penyesuaian, Neraca Saldo sesudah } \\
\text { Penyesuaian, Laporan Laba Rugi, Laporan Perubahan } \\
\text { Modal, dan Neraca Akhir. }\end{array}$ \\
\hline Logout & \begin{tabular}{l} 
Admin dan Staff dapat keluar dari sistem. \\
\hline
\end{tabular} \\
\hline
\end{tabular}


URL : https://jurnal.machung.ac.id/index.php/kurawal

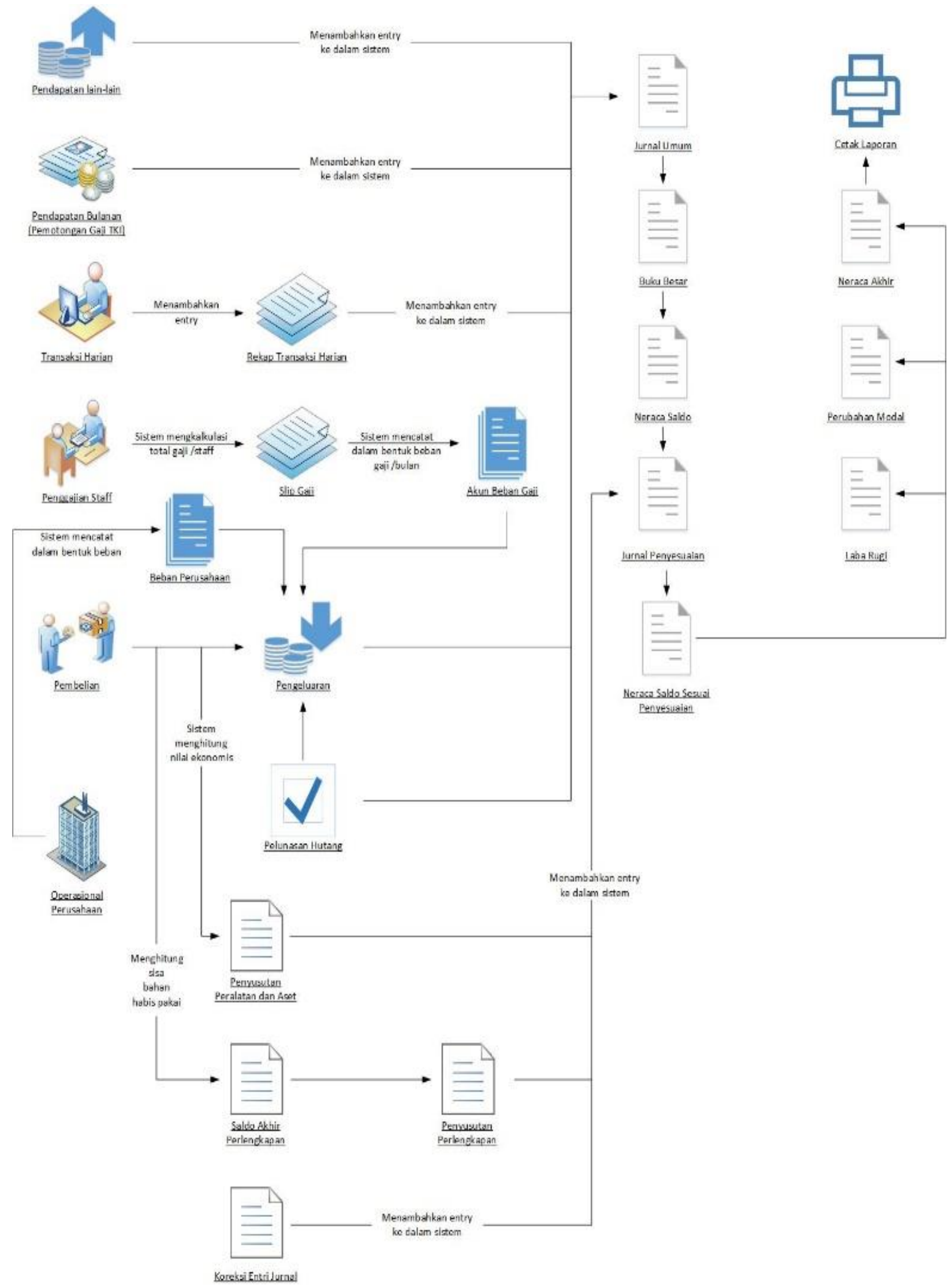

Gambar 1 workflow sistem baru 
URL : https://jurnal.machung.ac.id/index.php/kurawal

\subsection{Tahap Desain}

Pada tahap ini akan ditentukan mengenai penggambaran alur dari informasi yang dibutuhkan, dengan membuat desain use case, diagram aktivitas, desain mockup untuk menentukan menu yang akan ditampilkan, serta desain ERD (Entity Relational Diagram).

a. Use Case Diagram

Use Case merupakan pemodelan untuk kelakuan (behavior) sistem informasi yang akan dibuat". Use case mendeskripsikan sebuah interaksi antara satu atau lebih aktor dengan sistem informasi yang akan dibuat[3]. Pada gambar 2 akan ditampilkan mengenai use case diagram dari pelaporan akuntansi. Aktor kepala cabang dan admin keuangan dapat mengakses semua laporan akuntansi yang disediakan sistem.

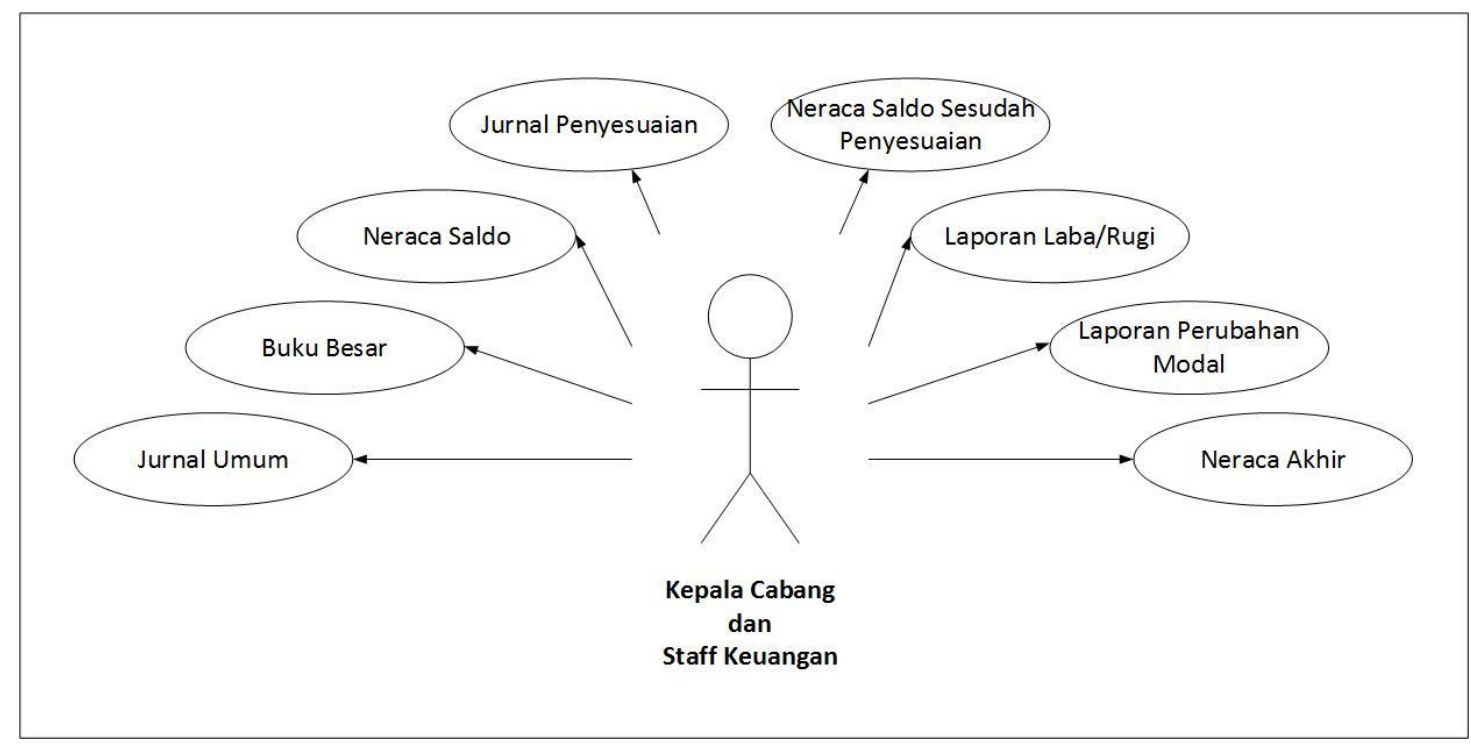

Gambar 2 Use Case Diagram Pelaporan 
b. Diagram Aktivitas

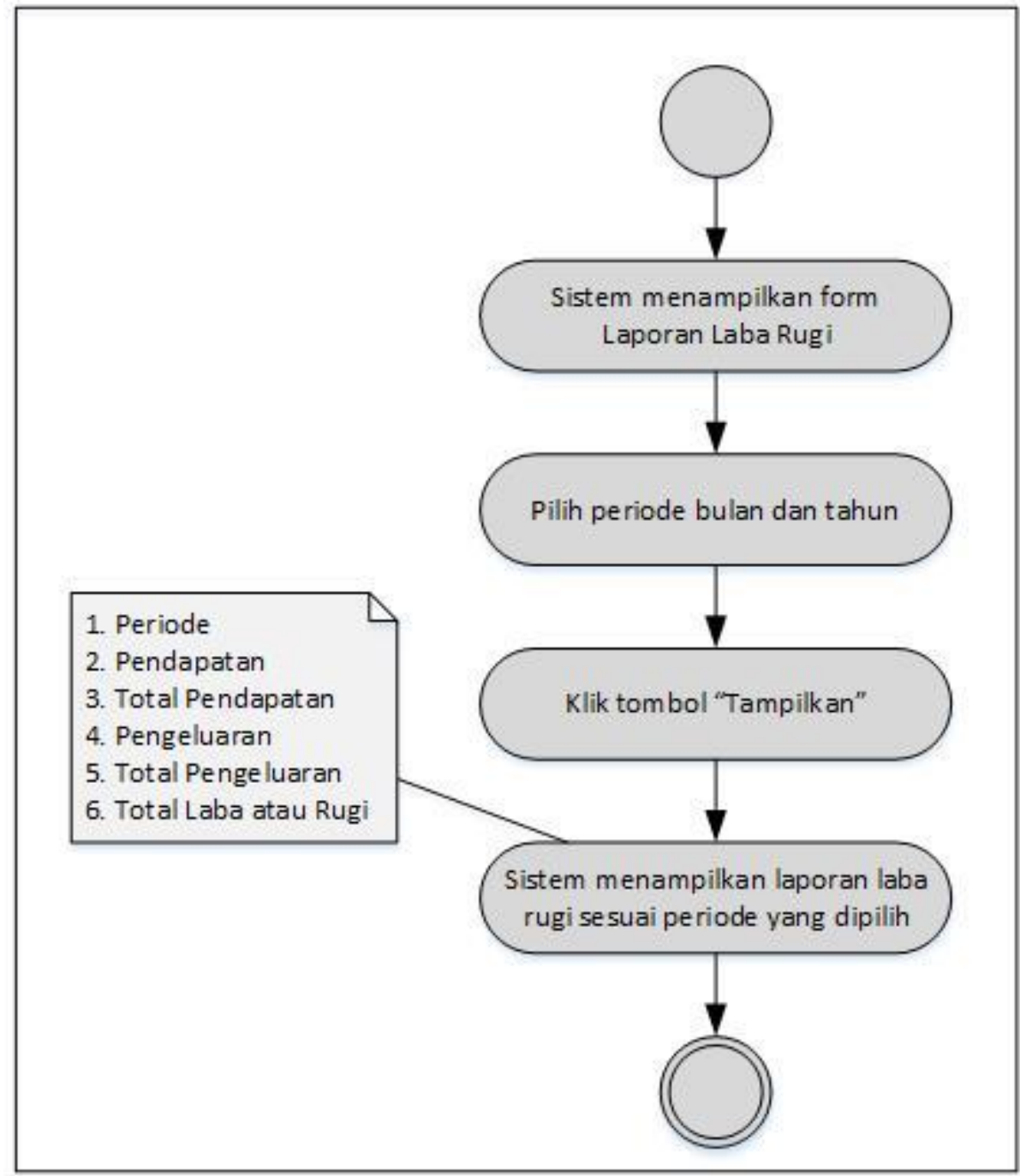

Gambar 3 Diagram Aktivitas Laporan Laba Rugi

Diagram aktivitas atau activity diagram menggambarkan workflow (aliran kerja) atau aktivitas dari sebuah sistem atau proses bisnis atau menu yang ada pada perangkat lunak. Activity Diagram menggambarkan aktivitas sistem bukan apa yang dilakukan aktor, jadi aktivitas yang dapat dilakukan oleh sistem. Pada gambar 3 akan ditampilkan mengenai diagram aktivitas dari laporan laba rugi.

c. Desain Mockup

Pada desain mockup akan digambarkan menu apa saja yang akan dibuat pada sistem. Pembuatan mockup dilihat berdasarkan diagram aktivitas yang telah dibuat sebelumnya. Pada gambar 4 akan ditampilkan mockup dari pelaporan laba rugi. 


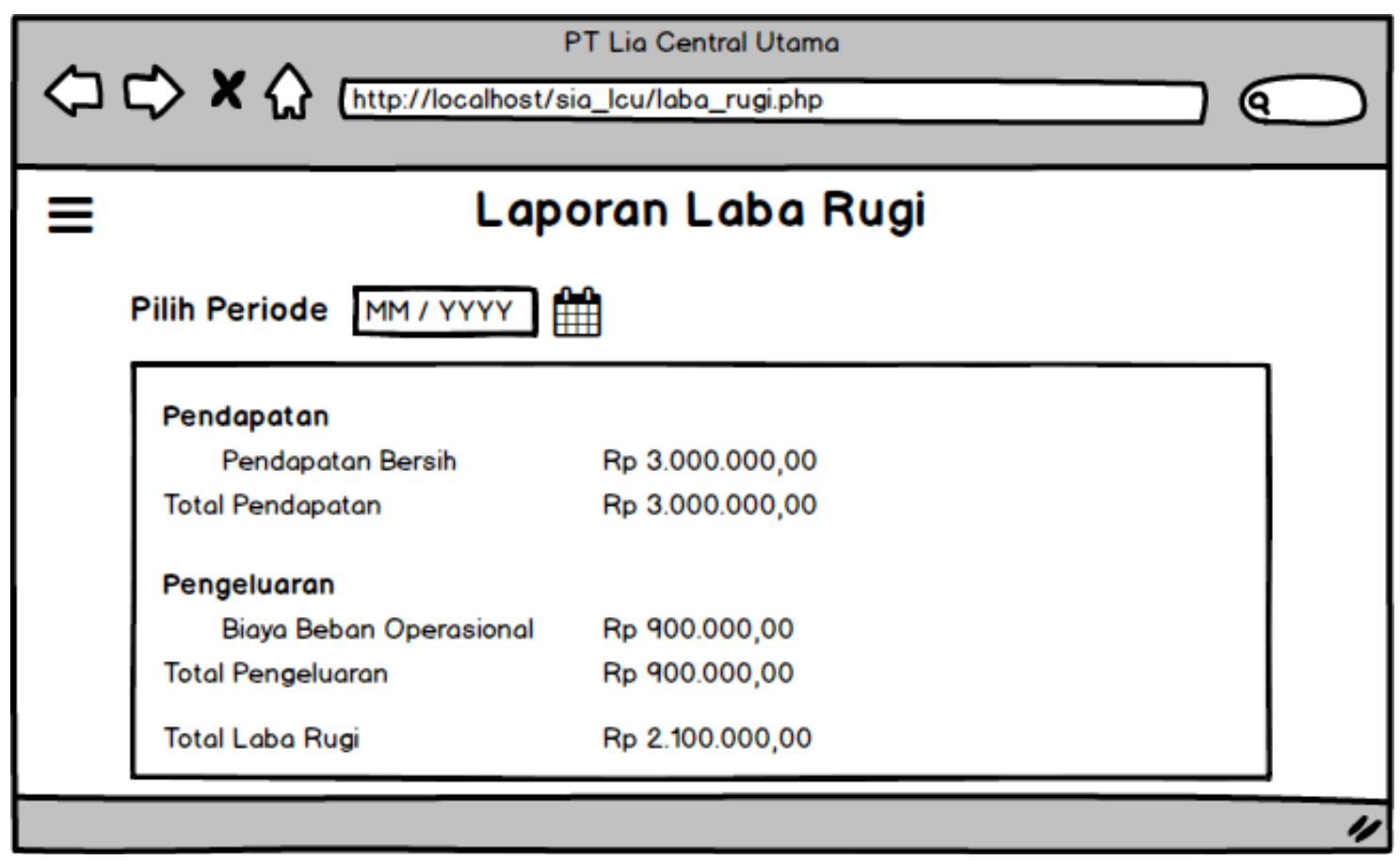

Gambar 4 Mockup Laporan Laba Rugi

d. Desain ERD

Entity Relational Diagram sendiri merupakan gambar atau diagram yang menunjukkan informasi dibuat, disimpan, dan digunakan dalam sistem bisnis. ERD merupakan suatu model untuk menjelaskan hubungan antar data dalam basis data berdasarkan objek-objek dasar data yang mempunyai hubungan antar relasi[4]. Pada gambar 5 akan ditampilkan mengenai desain dari ERD yang akan diterapkan pada database sistem. Database adalah sekumpulan data yang berisi informasi mengenai satu atau beberapa object. Data dalam database tersebut biasanya disimpan dalam tabel yang saling berhubungan antara satu dengan yang lain[5]. 
URL : https://jurnal.machung.ac.id/index.php/kurawal

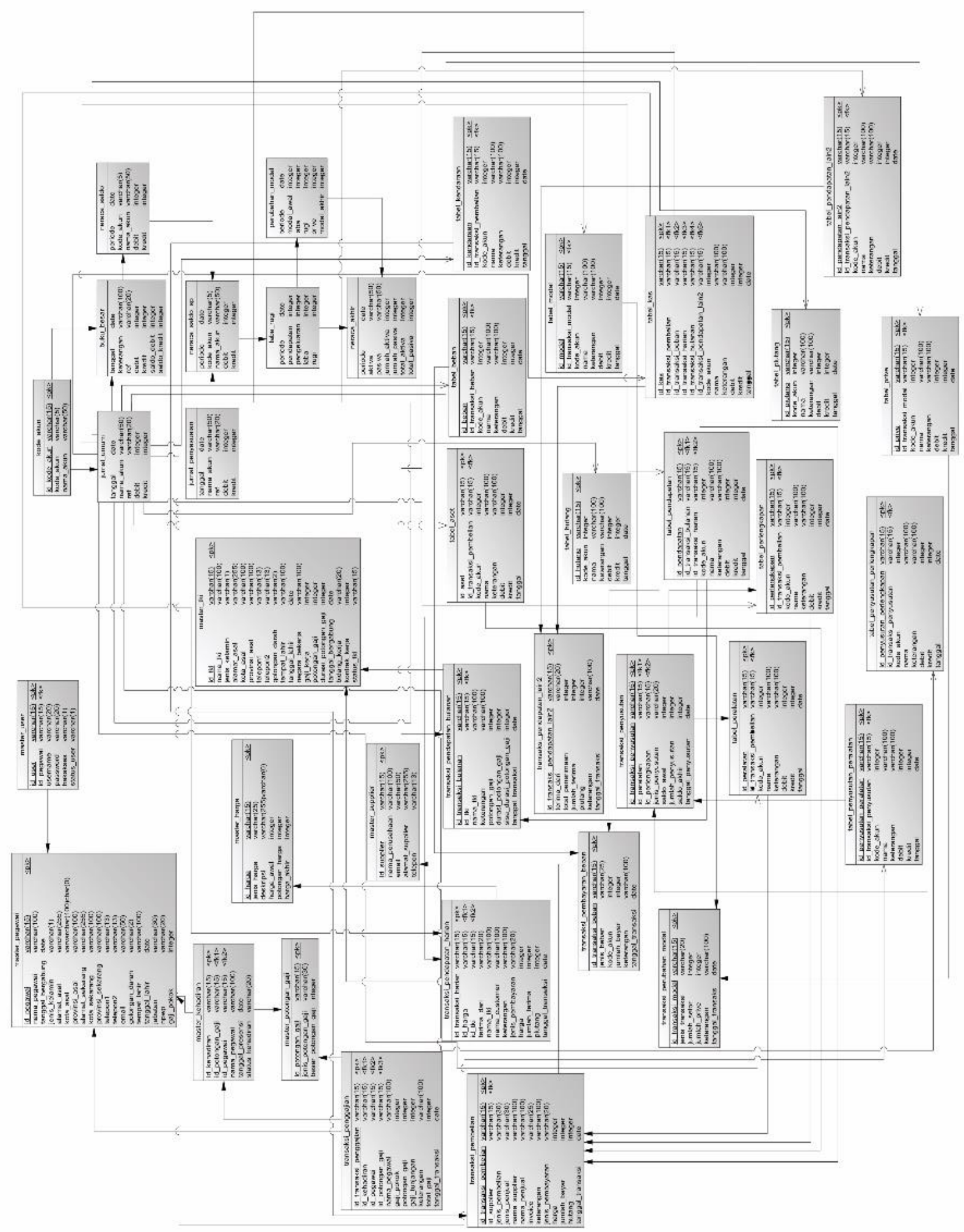

Gambar 5 Desain Entity Relational Diagram 
URL : https://jurnal.machung.ac.id/index.php/kurawal

\section{HASIL DAN PEMBAHASAN}

Hasil dari penelitian ini berupa sistem informasi akuntansi yang digunakan dalam pencatatan serta mengolah data mengenai perusahaan jasa tenaga kerja Indonesia (PT. Lia Central Utama). Aplikasi sistem informasi akuntansi ini disediakan beberapa halaman, diantaranya halaman login seperti pada gambar 6. Pembuatan aplikasi berbasi web ini menggunakan bahasa PHP, dimana PHP merupakan singkatan dari Hypertext Preprocessor yang digunakan sebagai bahasa script server-side dalam pengembangan Web yang disisipkan pada dokumen HTML. Saat ini PHP telah menginjak versi 7 dan tetap dapat di gunakan secara gratis, selain itu PHP mendukung pemrograman berorientasi obyek (PBO) atau Object Oriented Programming (OOP) sehingga saat ini banyak bermunculan Framework PHP[6]. Untuk menunjang bahasa pemrograman PHP ini sendiri juga dibutuhkan JavaScript yang merupakan modifikasi dari bahasa $\mathrm{C}++$ dengan pola penulisan yang lebih sederhana. Interpreter bahasa ini sudah disediakan ASP ataupun internet explorer. Kelebihan JavaScript adalah berinteraksi dengan HTML, ini membolehkan pembuat web untuk memasukkan web mereka dengan kandungan-kandungan yang dinamik, menukar warna background, menukar banner, efek mouse, menu interaktif dan sebagainya[7]. Sedangkan untuk tampilan desain web yang diterapkan menggunakan CSS. Cascading Style Sheet (CSS) merupakan salah satu bahasa pemrograman web untuk mengendalikan beberapa komponen dalam sebuah web sehingga akan lebih terstruktur dan seragam[8]. Dalam menerapkan database yang telah dibuat dalam bentuk ERD, maka diperlukan juga tools untuk merelasikan database dengan sistem menggunakan MySQL.

MySQL merupakan software RDBMS (atau server database) yang dapat mengelola database dengan sangat cepat, dapat menampung data dalam jumlah sangat besar, dapat diakses oleh banyak user (multi-user) dan dapat melakukan suatu proses secara sinkron atau berbarengan (multi-threaded)[9]. Untuk menjalankan sistem ini diperlukan aplikasi XAMPP dimana aplikasi ini nantinya akan membuka serta menjalankan sistem dan mengkoneksikan ke dalam database dalam waktu yang bersamaan. XAMPP adalah perangkat lunak bebas, yang mendukung banyak system operasi, merupakan kompilasi dari beberapa program. Fungsinya adalahsebagai server yang berdiri sendiri (localhost), yang terdiri atas program Apache HTTP Server, MySQL database, dan penerjemah bahasa yang ditulis dengan bahasa pemrograman PHP dan Perl[10]. 
URL : https://jurnal.machung.ac.id/index.php/kurawal

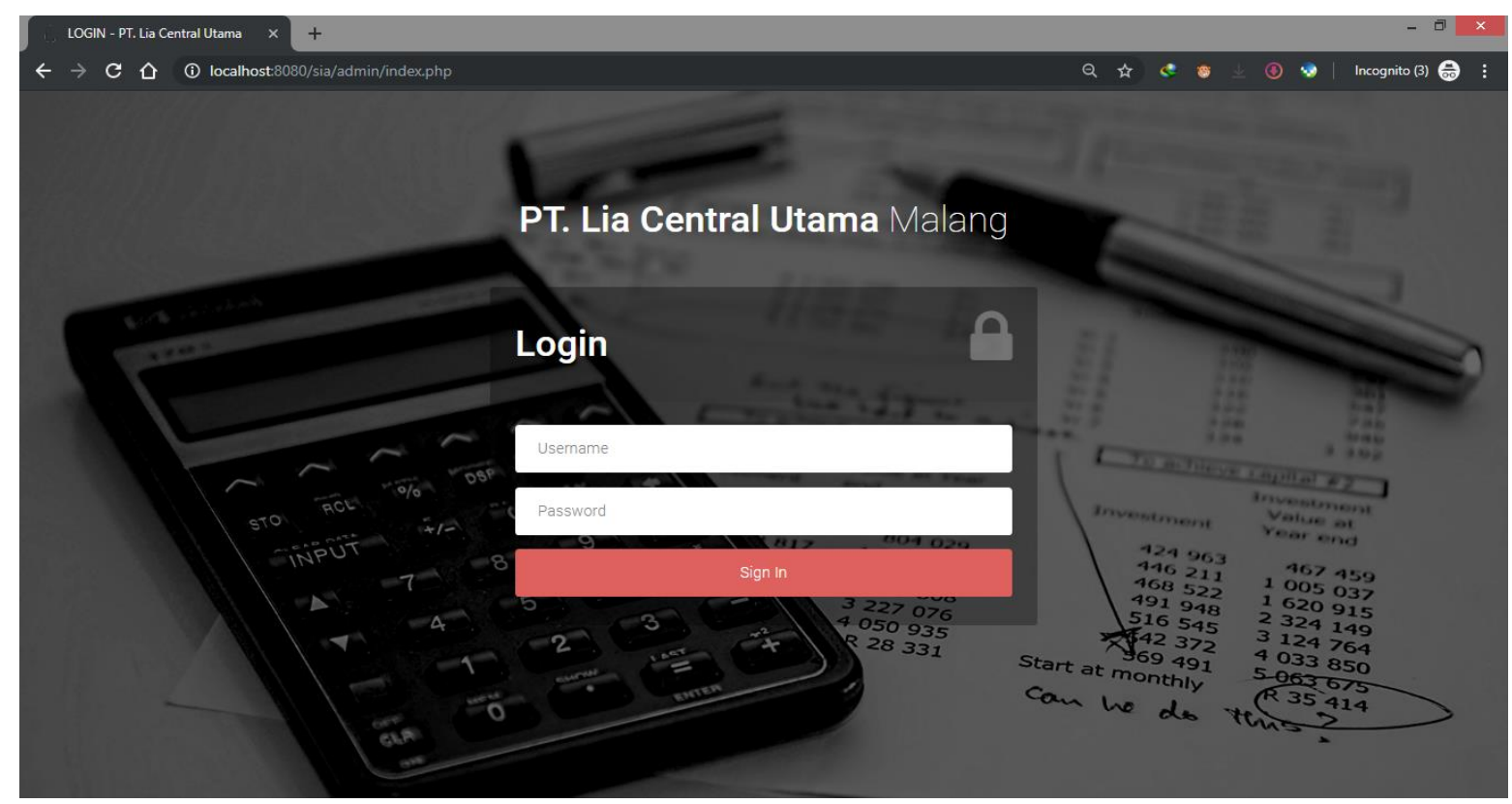

Gambar 6 Tampilan halaman login

Pada gambar 6 halaman login ini berfungsi untuk login user yang dibedakan menjadi tiga hak akses yakni hak akses untuk kepala cabang, admin keuangan, dan staff. Setelah login ke dalam sistem, maka user akan mendapatkan tampilan dashboard yang berbeda tiap hak aksesnya.

Pada gambar 7 merupakan tampilan dashboard untuk hak akses admin keuangan. Pada halaman ditampilkan mengenai informasi perusahaan serta informasi pribadi, di antaranya pendapatan pada hari ini, pendapatan pada bulan ini, total piutang berjalan, serta total hutang berjalan. 
URL : https://jurnal.machung.ac.id/index.php/kurawal

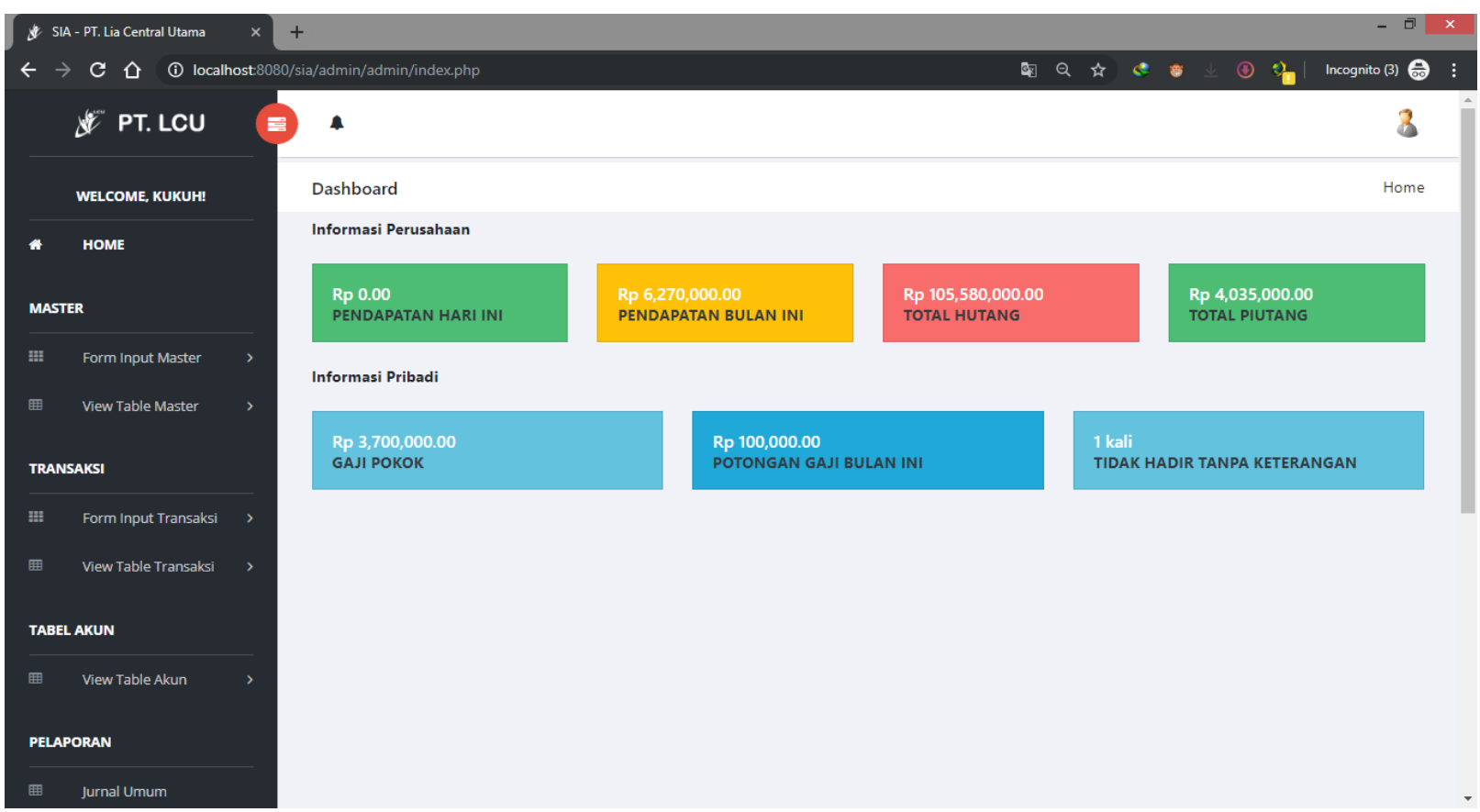

Gambar 7 Tampilan dashboard admin keuangan

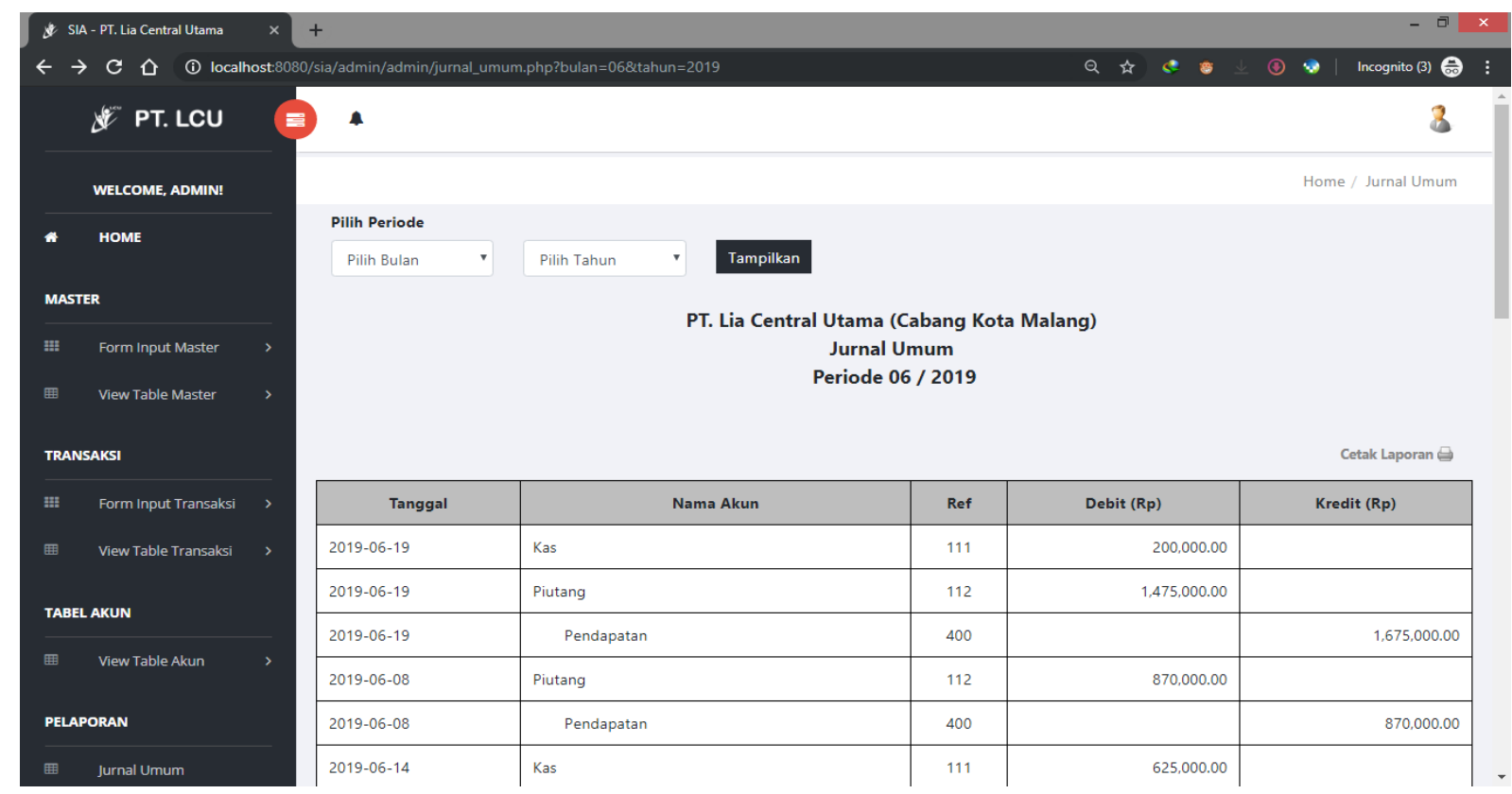

Gambar 8 Tampilan Pelaporan Jurnal Umum

Sedangkan untuk informasi pribadi ditampilkan data mengenai gaji pokok, potongan gaji bulan ini, serta total tidak hadiran tanpa keterangan dalam bulan ini.

Pada gambar 8 merupakan tampilan dari pelaporan jurnal umum. Pelaporan ini dapat diakses oleh kepala cabang dan admin keuangan. Pada halaman ini disediakan filter berdasarkan periode bulanan dan juga disediakan tombol cetak laporan. 
Pada gambar 9 merupakan tampilan dari pelaporan neraca saldo. Pelaporan ini dibuat setelah proses pembuatan jurnal umum dimana mengelompokkan data berdasarkan nama akun. Pelaporan ini dapat diakses oleh kepala cabang dan admin keuangan. Pada halaman ini disediakan filter berdasarkan periode bulanan dan juga disediakan tombol cetak laporan.

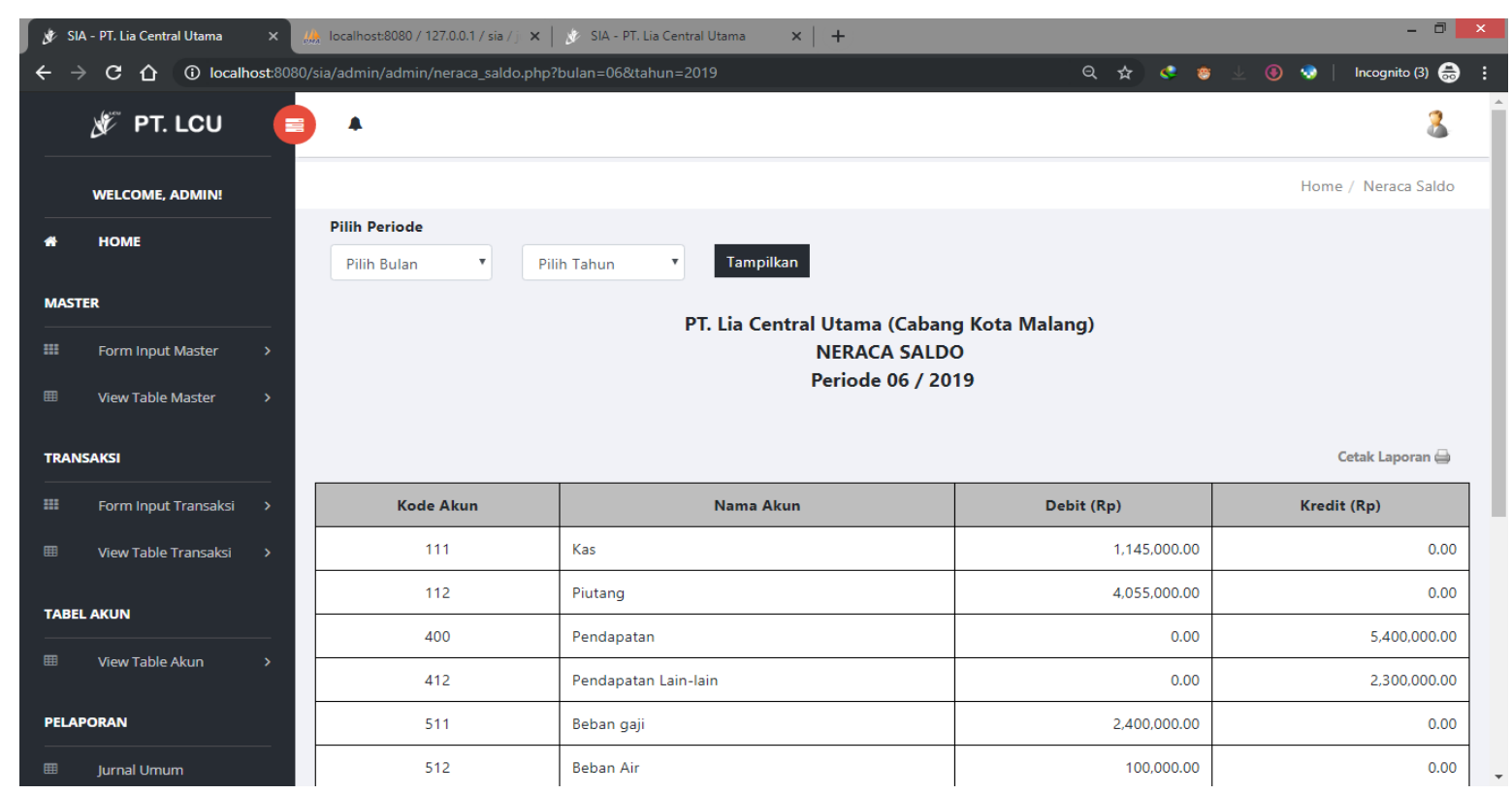

Gambar 9 Tampilan Pelaporan Neraca Saldo

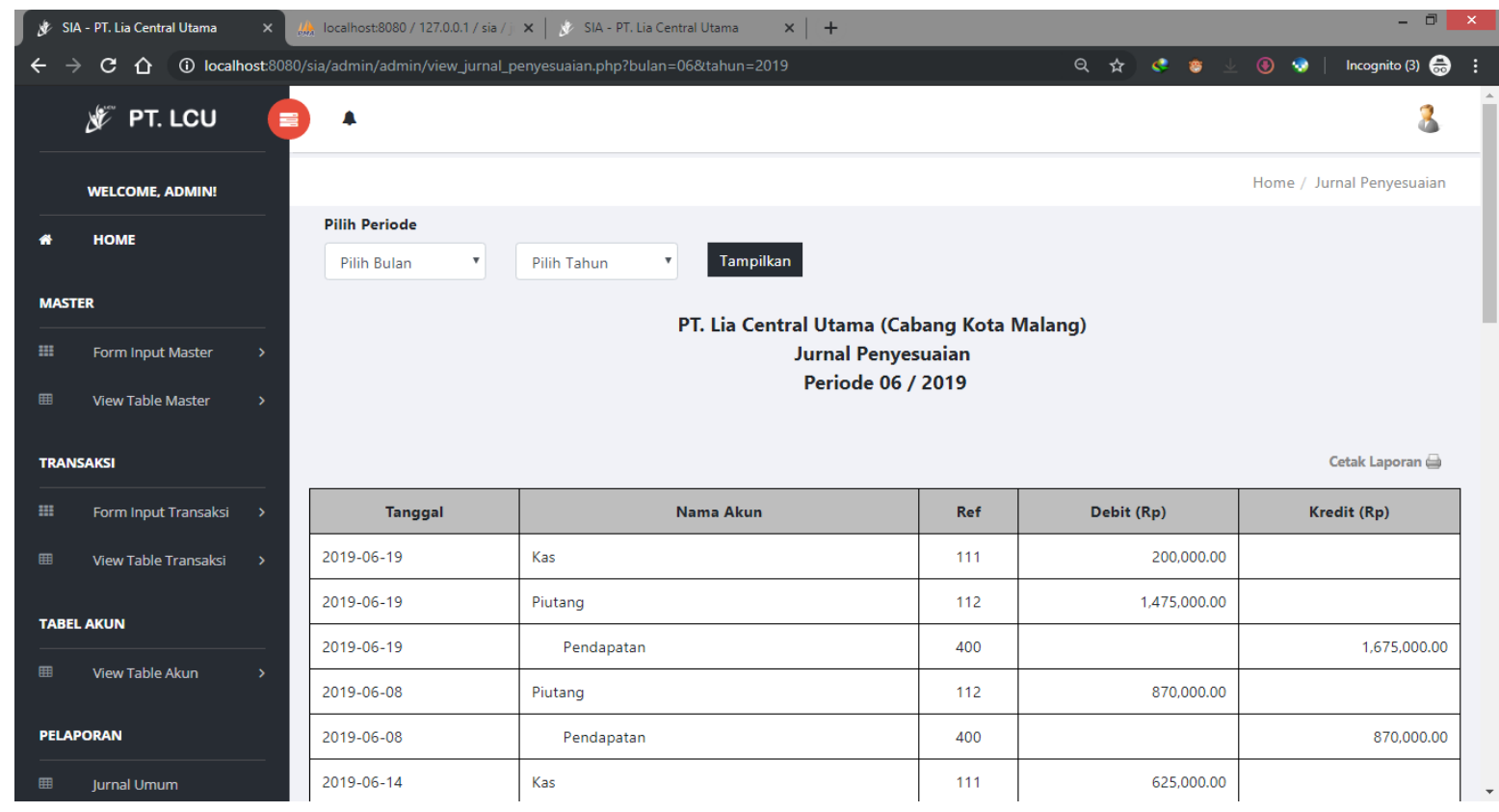

Gambar 10 Tampilan Pelaporan Jurnal Penyesuaian 
URL : https://jurnal.machung.ac.id/index.php/kurawal

Pada gambar 10 merupakan tampilan dari pelaporan jurnal penyesuaian. Pelaporan ini dibuat berdasarkan akhir periode untuk menyesuaikan data jurnal. Pelaporan ini dapat diakses oleh kepala cabang dan admin keuangan. Pada halaman ini disediakan filter berdasarkan periode bulanan dan juga disediakan tombol cetak laporan.

Pada gambar 11 merupakan tampilan dari pelaporan neraca saldo setelah penyesuaian. Pelaporan ini ditampilkan berdasarkan neraca saldo sebelum penyesuaian yang telah dikalkulasikan dengan pelaporan jurnal penyesuaian. Pelaporan ini dapat diakses oleh kepala cabang dan admin keuangan. Pada halaman ini disediakan filter berdasarkan periode bulanan dan juga disediakan tombol cetak laporan.

Pada gambar 12 merupakan tampilan dari pelaporan laba. Pelaporan ini dapat diakses oleh kepala cabang dan admin keuangan. Pada halaman ini disediakan filter berdasarkan periode bulanan dan juga disediakan tombol cetak laporan.

Pada gambar 13 merupakan tampilan dari laporan perubahan modal. Pelaporan ini dapat diakses oleh kepala cabang dan admin keuangan. Pada halaman ini disediakan filter berdasarkan periode bulanan dan juga disediakan tombol cetak laporan.

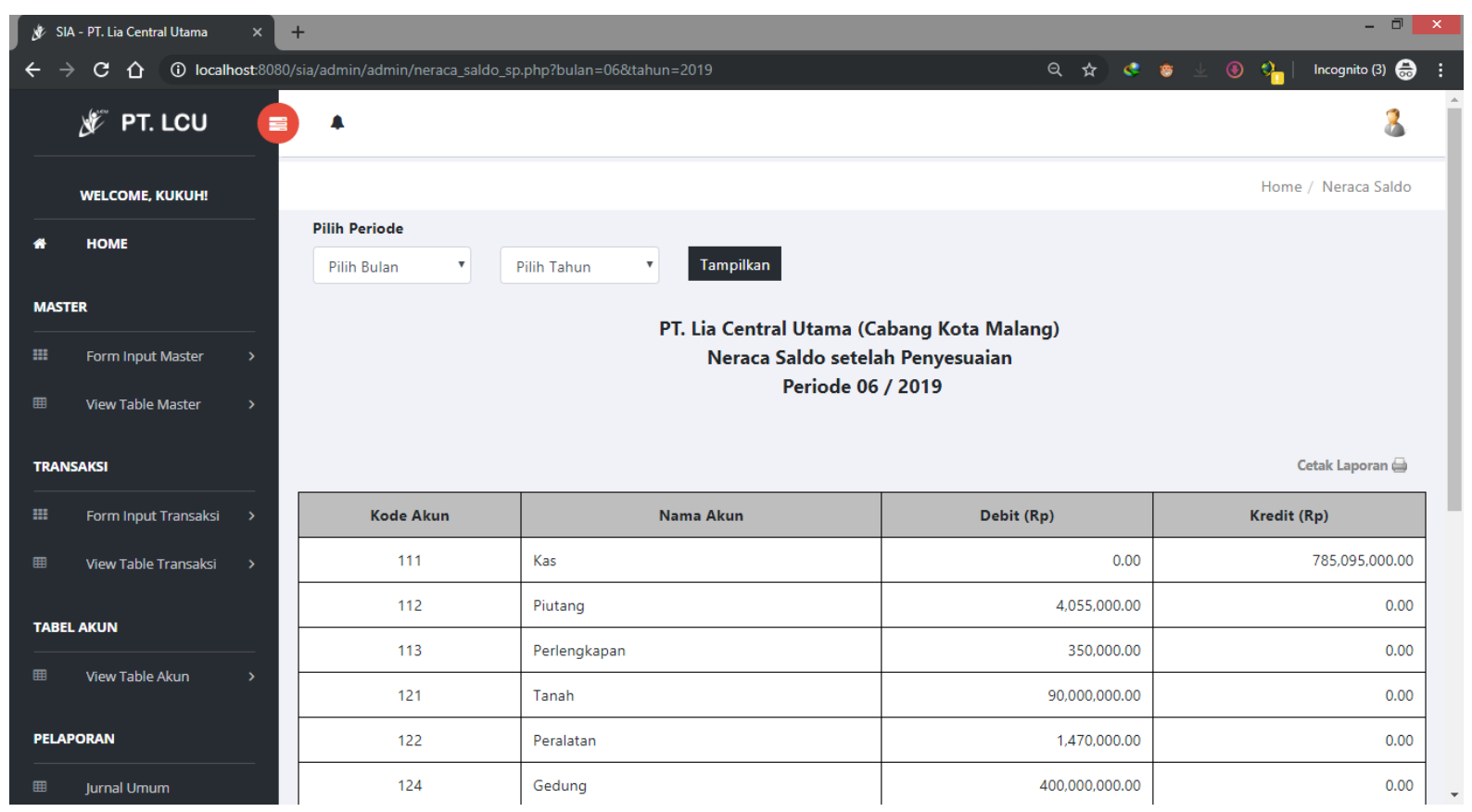

Gambar 11 Neraca Saldo setelah Penyesuaian 
URL : https://jurnal.machung.ac.id/index.php/kurawal

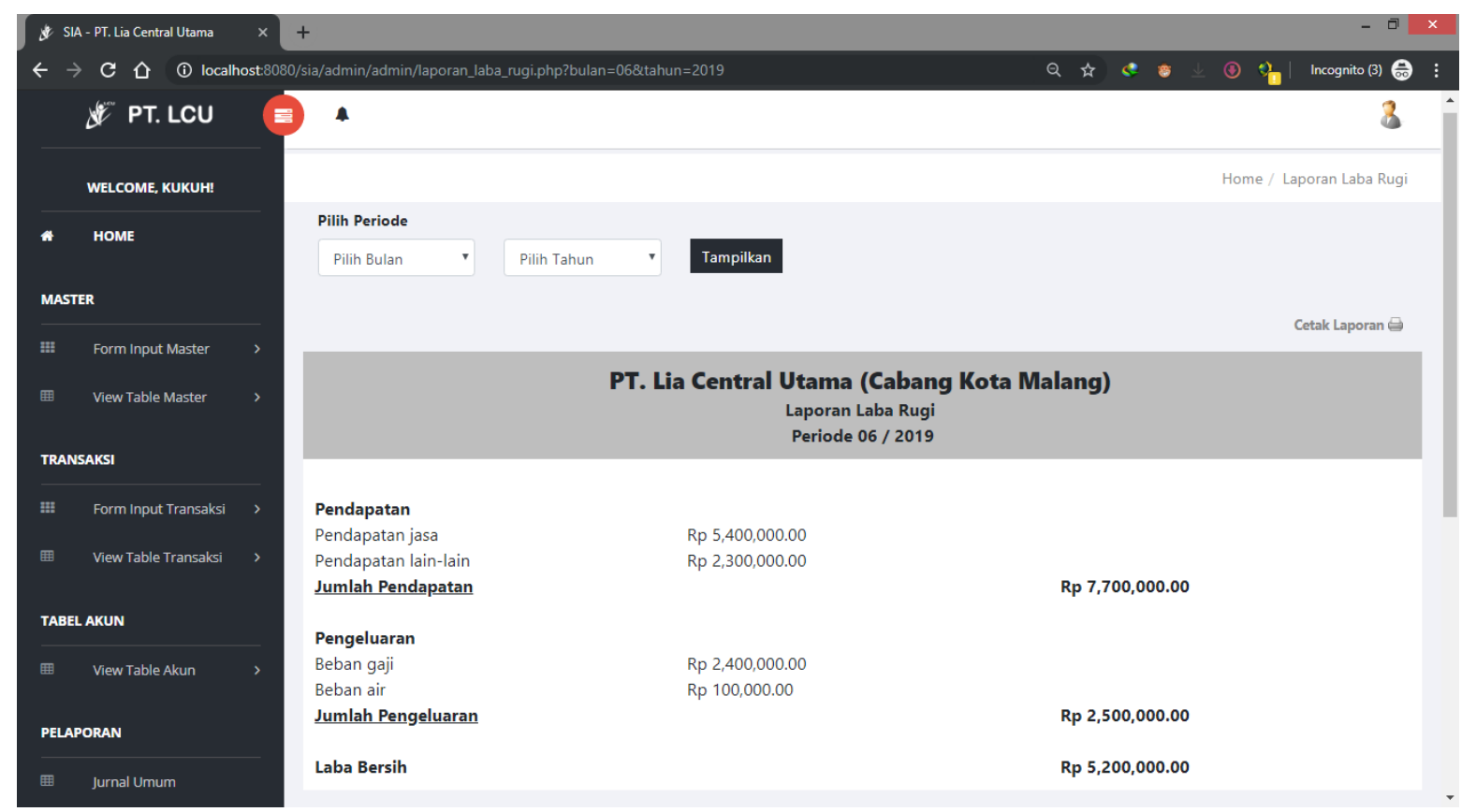

Gambar 12 Pelaporan Laba Rugi

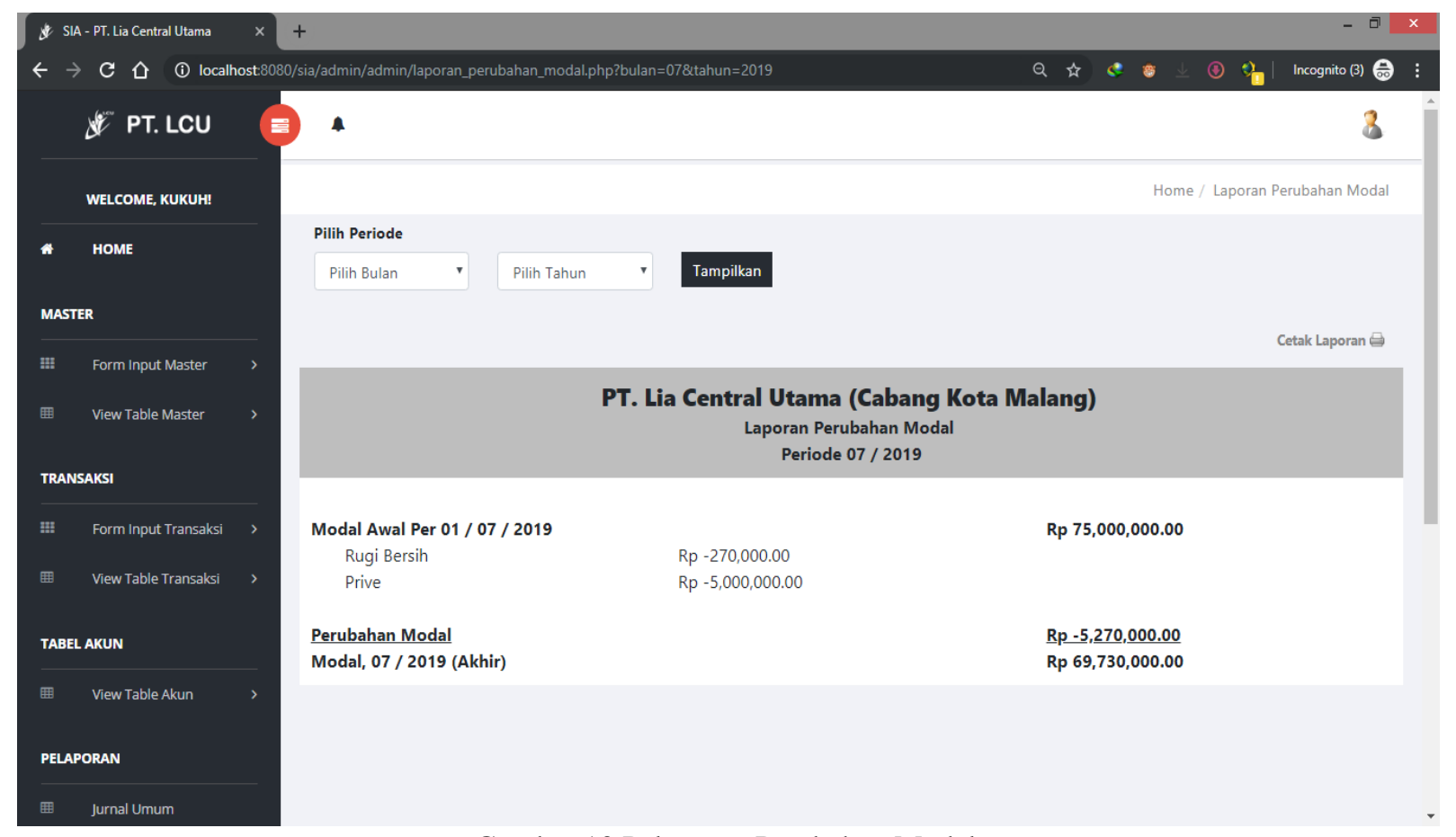

Gambar 13 Pelaporan Perubahan Modal 
URL : https://jurnal.machung.ac.id/index.php/kurawal

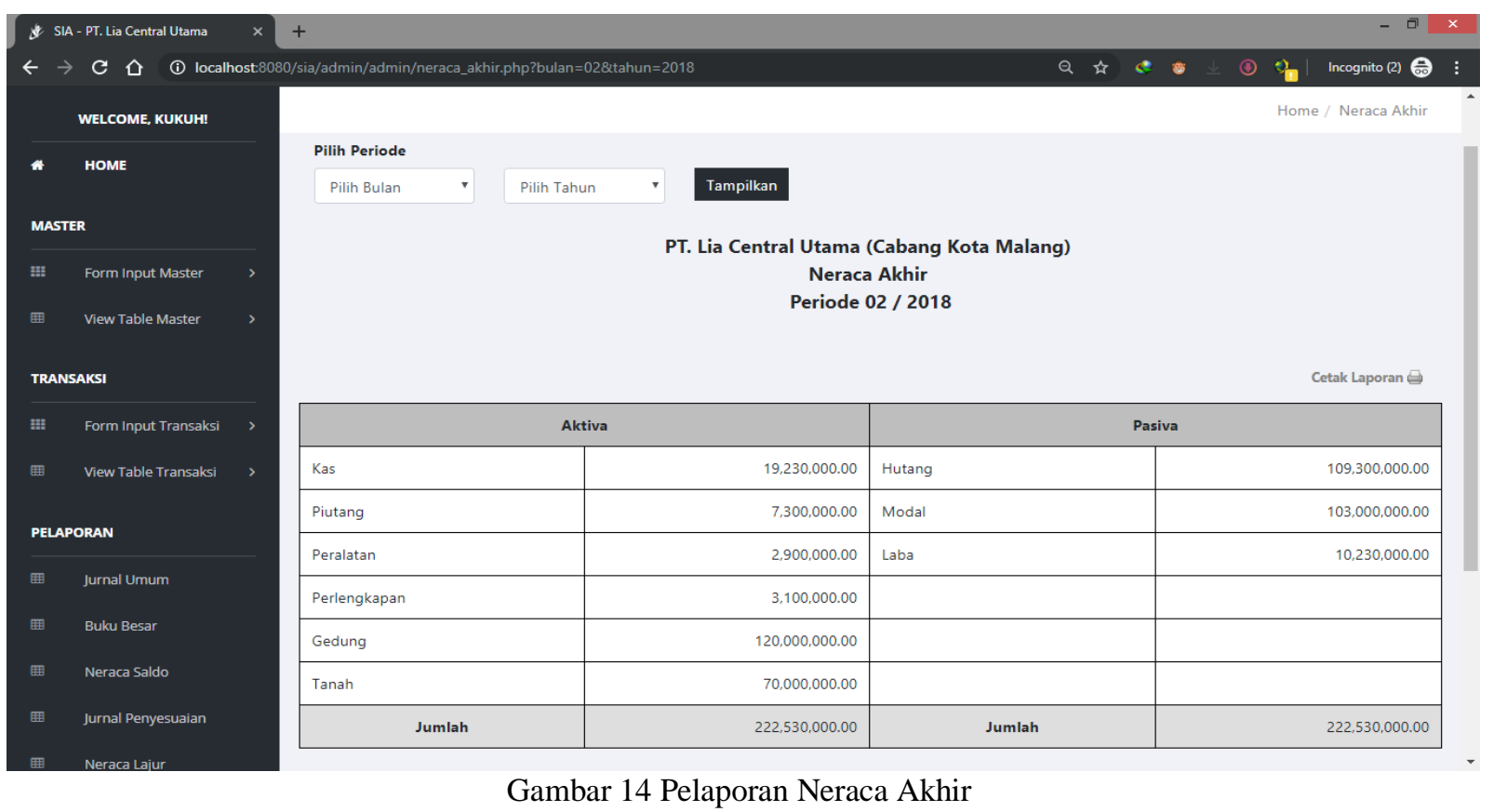

Pada gambar 14 merupakan tampilan dari laporan neraca akhir. Pelaporan ini dapat diakses oleh kepala cabang dan admin keuangan. Pada halaman ini disediakan filter berdasarkan periode bulanan dan juga disediakan tombol cetak laporan.

\section{KESIMPULAN}

Sistem informasi akuntansi pada perusahaan jasa Tenaga Kerja Indonesia (studi kasus: PT. Lia Central Utama Cabang Kota Malang) ini berbasis web dan dibangun dengan bahasa pemrograman PHP dan database MySQL. Dalam pembuatan sistem ini diterapkan metode System Development Life Cycle (SDLC). Sistem dikembangkan menyesuaikan proses bisnis perusahaan mulai dari pendapatan hingga pengeluaran sampai dengan detail untuk biaya operasional perusahaan. Sistem ini dapat membantu perusahaan untuk mencatat pendapatan harian hingga bulanan serta pendapatan lain-lain, mencatat pengeluaran perusahaan seperti biaya operasional perusahaan, mencatat transaksi pembelian hingga pelunasan hutang perusahaan, melihat pelaporan akuntansi perusahaan sesuai periode bulanan, serta mencetak pelaporan akuntansi perusahaan sesuai periode bulanan.

Sistem yang telah dibuat masih dapat dikembangkan lebih jauh lagi, seperti pembuatan sistem berbasis mobile dari android untuk mengikuti perkembangan terkini serta efisien karena dapat diakses di mana saja tanpa terhalang tempat dan waktu. Oleh karena itu, diharapkan untuk ke depannya dapat dikembangkan lagi sistem ini dengan menyediakan sistem yang berbasis 
URL : https://jurnal.machung.ac.id/index.php/kurawal

android untuk mobile sehingga dapat diakses dimanapun dan kapanpun tanpa terhalang tempat dan waktu.

\section{DAFTAR PUSTAKA}

[1] Darwin, Muhadjir, dkk., 2015, Mobilitas Lintas Batas di Kawasan Asia Tenggara dan Sekitarnya, Pusat Studi Kependudukan dan Kebijakan.

[2] Ladjamudin, Al-Bahra Bin., 2015, Analisis dan Desain Sistem Informasi, Graha Ilmu.

[3] Rosa, Ariani Sukamto dan Shalahuddin M., 2014, Rekayasa Perangkat Lunak Terstruktur dan Berorientasi Objek, Informatika.

[4] Al Fatta, Hanif., 2017, Analisis \& Perancangan Sistem Informasi; untuk Keunggulan Bersaing Perusahaan \& Organisasi Modern, Andi.

[5] Musyawarah, Rina., 2015, Membangun Aplikasi Data Base Berbasis Web untuk Pemula. Elex Media Komputindo Kelompok Gramedia, Anggota IKAPI.

[6] Peranginangin, Kasiman., 2016, Aplikasi WEB dengan PHP dan MySQL, Andi.

[7] Kadir, Abdul., 2015, Pemrograman Web Mencakup : HTML , CSS , JAVASCRIPT \& PHP, Andi Offset

[8] Ardhana, Kusuma., 2015 PHP Menyelesaikan Website 30 Juta. Banyumas.

[9] Raharjo, Budi., 2016, Modul Pemrograman Web html, Php dan MySql, Modula.

[10] Aditya, Nur Alan., 2015, Jago PHP \& MySQL, Dunia Komputer. 